\title{
Clinical characteristics, injury pattern and management of pediatric pelvic fracture: An observational retrospective study from a level I trauma center
}

Abduljabbar Alhammoud ${ }^{1}$ Isam Moghamis ${ }^{1}$, Husham Abdelrahman², Syed Imran Ghouri ${ }^{1}$, Mohammad Asim³, Elhadi Babikir ${ }^{1}$, Hassan Al-Thani ${ }^{2}$ and Ayman El-Menyar ${ }^{3,4^{*}}$

\begin{abstract}
Background: Pediatric pelvic fractures (PPF) are uncommon among children requiring hospitalization after blunt trauma. The present study explored our experience for the prevalence, patients demographics, clinical characteristics, injury pattern and management of pediatric pelvic fractures in a level I trauma center.

Methods: This is a retrospective review of prospectively collected data obtained from trauma registry database for all pediatrics trauma patients of age $\leq 18$ years. Data were analyzed according to different aspects relevant to the clinical applications such as Torode classification for pelvic ring fracture (Type I-IV), open versus closed triradiate cartilage, and surgical versus non-surgical management.

Results: During the study period (3 and half years), a total of 119 PPF cases were admitted at the trauma center (11\% of total pediatric admissions); the majority had pelvic ring fractures (91.6\%) and $8.4 \%$ had an acetabular fracture. The mean age of patients was $11.5 \pm 5.7$, and the majority were males (78.2\%). One hundred and four fractures were classified as type I (5.8\%), type II (13.5\%), type III (68.3\%) and type IV (12.5\%). Patients in the surgical group were more likely to have higher pelvis AIS $(p=0.001)$, type IV fractures, acetabular fractures and closed triradiate cartilage as compared to the conservative group. Type III fractures and open triradiate cartilage were significantly higher in the conservative group $(p<0.05)$. Patients with closed triradiate cartilage frequently sustained spine, head injuries, acetabular fracture and had higher mean ISS and pelvis AIS $(p<0.01)$ than the open group. However, the rate of in-hospital complications and mortality were comparable among different groups. The overall mortality rate was $2.5 \%$.
\end{abstract}

\footnotetext{
* Correspondence: aymanco65@yahoo.com

${ }^{3}$ Clinical Research, Trauma \& Vascular Surgery, Department of Surgery,

Hamad General Hospital, HMC, Doha, Qatar

${ }^{4}$ Department of Clinical Medicine, Weill Cornell Medical School, Doha, Qatar

Full list of author information is available at the end of the article
}

(c) The Author(s). 2021 Open Access This article is licensed under a Creative Commons Attribution 4.0 International License, which permits use, sharing, adaptation, distribution and reproduction in any medium or format, as long as you give appropriate credit to the original author(s) and the source, provide a link to the Creative Commons licence, and indicate if changes were made. The images or other third party material in this article are included in the article's Creative Commons licence, unless indicated otherwise in a credit line to the material. If material is not included in the article's Creative Commons licence and your intended use is not permitted by statutory regulation or exceeds the permitted use, you will need to obtain permission directly from the copyright holder. To view a copy of this licence, visit http://creativecommons.org/licenses/by/4.0/ The Creative Commons Public Domain Dedication waiver (http://creativecommons.org/publicdomain/zero/1.0/) applies to the data made available in this article, unless otherwise stated in a credit line to the data. 
Conclusion: PPF are uncommon and mainly caused by high-impact trauma associated with multisystem injuries. The majority of PPF are stable, despite the underlying high-energy mechanism. Management of PPF depends on the severity of fracture as patients with higher grade fractures require surgical intervention. Furthermore, larger prospective study is needed to understand the age-related pattern and management of PPF.

Keywords: Pediatric pelvic fracture, Fracture classification, Pelvic ring injury, Polytrauma

\section{Introduction}

Pediatric pelvic fractures (PPF) are uncommon with the reported incidence ranges between 0.3 and $4.0 \%$ among children required hospitalization after blunt trauma [1,2]. This frequency of pelvic fractures is relatively lower in pediatrics as compared to adults which could be attributed to the existence of anatomical differences between the two populations [3]. The skeletally immature pediatric pelvis has several physical properties which makes it distinct from adults with respect to the injury patterns, management, and outcomes [4]. The differences include the presence of larger cartilage component in the immature bone with increased porosity of the cortical bone, greater elasticity of the pubic symphysis and the sacroiliac joint [5-7].

High-energy blunt trauma is the leading mechanism of pediatric pelvic fractures primarily due to motor vehicle accidents and fall from height [2-4]. Pelvic fracture in pediatric population is a marker of the injury severity which showed association with injuries to the head and intra-abdominal region and greater risk of hemorrhage $[2,8,9]$. Hemorrhage as reported in adult pelvic fractures that leads to hemodynamic instability is rarely observed in pediatric pelvic fracture $[2,10]$. Usually solid organ injuries resulted from high-energy trauma are mostly the primary source of bleeding in children $[1,2$, 11]. The adults have higher rate of mortality secondary to the pelvic fracture than the pediatric patients, in which death occurs primarily due to injuries to other body regions particularly the head $[1,8,12]$.

Determination of the pattern and complexity of pediatric pelvic fracture is key for optimum management [13]. Closure of triradiate cartilage has been suggested as a distinguishing biological factor between the pediatric and adult pelvis. This factor makes the role of CT scan extremely essential for the diagnosis and management of PPF $[14,15]$.

Notably, simple pelvic ring injuries are the predominant type of fracture among children. Usually, PPF does not require surgical intervention as they are mostly nondisplaced fractures. However, rare fractures involving the triradiate cartilage or the acetabulum as well as significant displaced fracture may require surgical management [16]. To date, there is limited literature available regarding the prevalence and outcome of pediatric pelvic fractures in the Arab Middle Eastern region. The present study explores a 3 and half year experience for pediatric pelvic fractures in a level I trauma center.

\section{Methods}

This is a retrospective review of prospectively collected data obtained from trauma registry database at Hamad General Hospital (HGH) which has a designated as the only level 1 trauma center in the country. The trauma registry has regular internal and external validation and linked to the National Trauma Data Bank (NTDB) in the USA. Data were collected for all pediatrics polytrauma patients of age less than or equal to 18 years who were presented and treated at $\mathrm{HGH}$ between January 2013 and June 2016.

Variables collected and analyzed included demographic data (age, gender, nationality), mechanism of injury details, associated injuries, Glasgow Coma Score (GCS) at emergency department (ED), Injury Severity Score (ISS), Revised Trauma Score (RTS), Abbreviated Injury scores (AIS), initial vital signs, ED disposition, Focused assessment with sonography for trauma (FAST), need for intubation and blood transfusion, number of blood units transfused, massive transfusion protocol (MTP), Torode fracture classification, acetabular fracture, triradiate cartilage (open or closed), management (conservative, surgical), in-hospital complications such as pneumonia, sepsis, Acute Respiratory Distress Syndrome (ARDS), Acute Kidney Injury (AKI), deep vein thrombosis (DVT), ventilatory days, ICU length of stay, hospital length of stay and in-hospital mortality.

The proposed Torode and Zieg system for pediatric pelvic fractures was used to classify each pelvic fracture pattern which categorizes pelvic fractures into four main types [17]. Type I represents fractures of bony prominences in avulsion; type II shows iliac crest fractures; type III corresponds to simple fractures of the pelvic ring without instability and type IV are complex fractures of the pelvic ring with instability. Grade IV is the most common indication of surgery.

Common types of surgical fixation of pediatric pelvic/ acetabulum fractures include (1) ORIF of pelvis (plating symphysis pubic, plating of iliac bone)-For Torode I \& II if there displacement more than $2-3 \mathrm{~cm}$ ). (2) ORIF acetabulum-for comminuted fracture with displacement or articular step off more than $2 \mathrm{~mm}$ or in presence of 
intraarticular fragments, open fracture and in cases of central hip dislocations. (3) Pelvic external fixation to reduce pelvic volume to treat hemodynamic instability status. (4) Pinning or screw fixation of sacroiliac joint if there is widening/diastasis.

Ethical approval for this study was obtained from Research Ethics Committee, Medical Research Center at Hamad Medical Corporation (HMC) (IRB\# 16395/16).

Statistical analysis: descriptive analyses were reported as frequencies and percentages for categorical variables. Continuous variables' central tendency was described using means and standard deviations for variables with normal distribution and median and range for variables with nonnormal distribution. Data were analyzed according to Torode classification for pelvic ring fracture (Type I-IV), open versus closed triradiate cartilage, and surgical versus non-surgical management. The continuous variables were analyzed using
Student's t-test and one-way ANOVA, as appropriate. Yates' corrected chi-square was used for categorical variables, if the expected cell frequencies were below 5 . For skewed continuous data non-parametric Mann-Whitney test was performed. A two-tailed $p$ value of $<0.05$ was considered statistically significant. Data analysis was carried out using the Statistical Package for the Social Sciences, version 21 (SPSS, Inc., Chicago, IL).

\section{Results}

During the study period, there were 5891 trauma admissions; of them $1070(18 \%)$ were pediatric patients $(\leq 18$ years old). Among the pediatric admissions, there were 119 (11\%) who had pelvic fractures. Figure 1 shows the study design (diagnosis and management). The majority were pelvic ring fractures $(n=109 ; 91.6 \%)$ while only 10 patients $(8.4 \%)$ had an acetabular fracture. The mean age

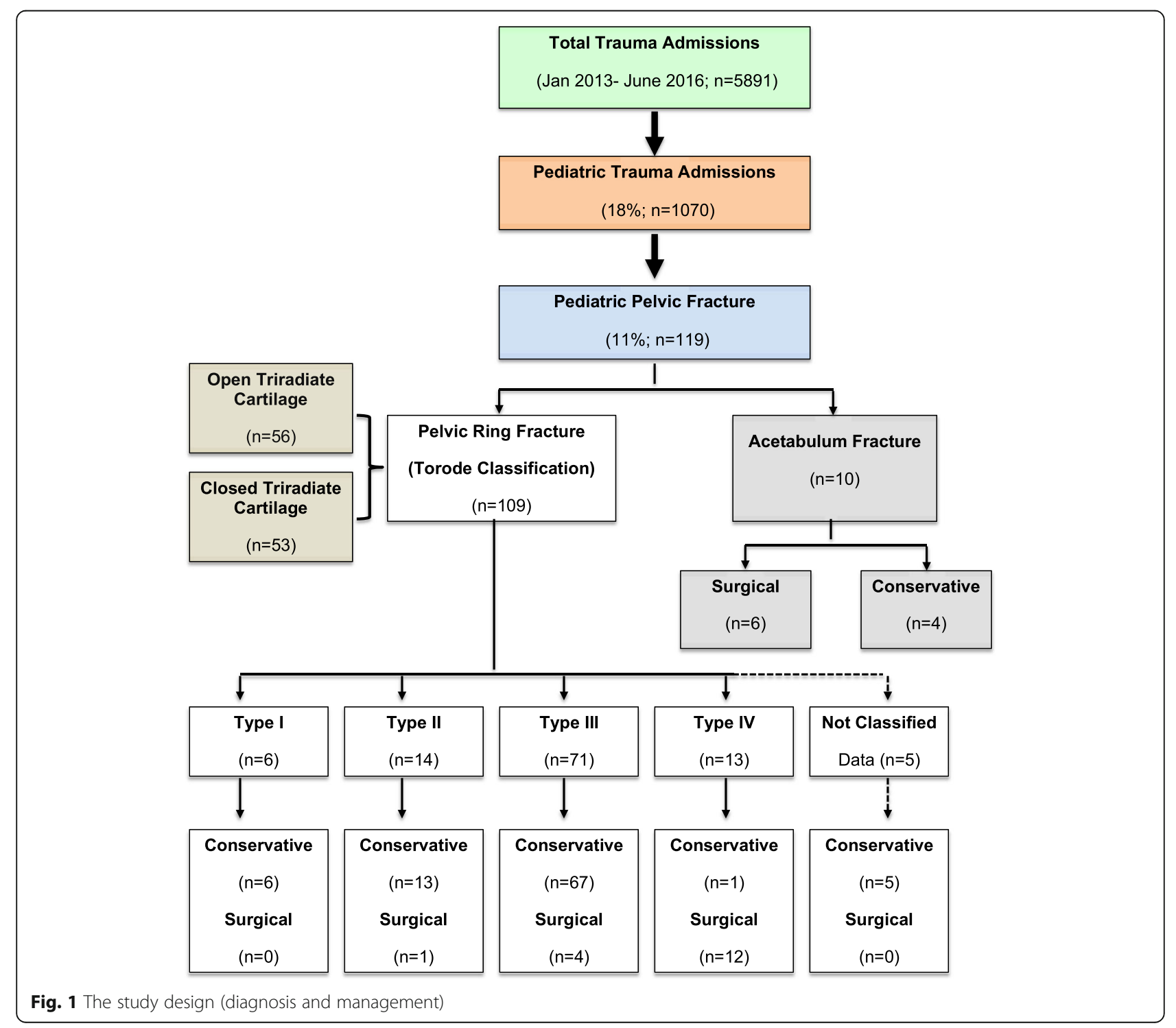


of patients was $11.5 \pm 5.7$ years, and the majority were males (78.2\%) (Table 1). MVC was the mechanism of injury in half of the patients $(52.9 \%)$, followed by pedestrian hit by car in a quarter (23.5\%) and fall from height $(12.6 \%)$. The most frequently associated injured body region was the chest (46.2\%) followed by the abdomen (34.5\%), spine (26.9\%), head (24.4\%), and lower extremity (17.6\%).

Only 7 (5.9\%) patients had pelvic hematoma with pelvic fracture, and the FAST was positive in $11 \%$ cases.

Table 1 Demographics, clinical presentation and outcome of pediatric pelvic fracture based on management

\begin{tabular}{|c|c|c|c|c|}
\hline & Overall $n=119$ & Conservative $(n=96 ; 80.7 \%)$ & Surgery $(n=23 ; n=19.3 \%)$ & $P$ value \\
\hline Age in years (mean \pm SD & $11.5 \pm 5.8$ & $11.1 \pm 5.8$ & $13.5 \pm 5.5$ & 0.06 \\
\hline Males \% & $93(78.2 \%)$ & 75 (78.1\%) & $18(78.3 \%)$ & 0.98 \\
\hline \multicolumn{5}{|l|}{ Mechanism of injury \% } \\
\hline Motor vehicle crashes & $63(52.9 \%)$ & $46(47.9 \%)$ & $17(73.9 \%)$ & \multirow[t]{4}{*}{0.17 for all } \\
\hline Fall & $15(12.6 \%)$ & $13(13.5 \%)$ & $2(8.7 \%)$ & \\
\hline Pedestrian & $28(23.5 \%)$ & $24(25.0 \%)$ & $4(17.4 \%)$ & \\
\hline Others & $13(10.9 \%)$ & $13(13.6 \%)$ & $0(0.0 \%)$ & \\
\hline \multicolumn{5}{|l|}{ Associated injuries \% } \\
\hline Chest & $55(46.2 \%)$ & 49 (51.0\%) & $6(26.1 \%)$ & 0.03 \\
\hline Spine & $32(26.9 \%)$ & $26(27.1 \%)$ & $6(26.1 \%)$ & 0.92 \\
\hline Abdomen & 41 (34.5\%) & $34(35.4 \%)$ & $7(30.4 \%)$ & 0.65 \\
\hline Head & 29 (24.4\%) & $26(27.1 \%)$ & $3(13.0 \%)$ & 0.15 \\
\hline Lower extremity & $21(17.6 \%)$ & $17(17.7 \%)$ & $4(17.4 \%)$ & 0.97 \\
\hline Injury Severity Score (mean \pm SD) & $16.2 \pm 11.0$ & $15.9 \pm 10.5$ & $17.0 \pm 13.3$ & 0.68 \\
\hline Revised Trauma Score (mean \pm SD) & $7.3 \pm 1.2$ & $7.3 \pm 1.2$ & $7.6 \pm 0.8$ & 0.14 \\
\hline Pelvis AIS & $2.2 \pm 0.6$ & $2.1 \pm 0.4$ & $2.7 \pm 0.9$ & 0.001 \\
\hline \multicolumn{5}{|l|}{ Torode fracture classification $\%(n=104)$} \\
\hline Type I & $6(5.8 \%)$ & $6(6.9 \%)$ & $0(0.0 \%)$ & \multirow[t]{4}{*}{0.001 for all } \\
\hline Type II & $14(13.5 \%)$ & $13(14.9 \%)$ & $1(5.9 \%)$ & \\
\hline Type III & $71(68.3 \%)$ & $67(77.0 \%)$ & $4(23.5 \%)$ & \\
\hline Type IV & $13(12.5 \%)$ & $1(1.1 \%)$ & $12(70.6 \%)$ & \\
\hline Acetabular fracture $\%$ & $10(8.4 \%)$ & $4(4.2 \%)$ & $6(26.1 \%)$ & 0.001 \\
\hline Open triradiate cartilage $\%$ & $56(51.4 \%)$ & 49 (56.3\%) & $7(31.8 \%)$ & \multirow[t]{2}{*}{0.04 for all } \\
\hline Closed triradiate cartilage $\%$ & $53(48.6 \%)$ & $38(43.7 \%)$ & $15(68.2 \%)$ & \\
\hline Intubation \% & $24(20.2 \%)$ & $21(21.9 \%)$ & $3(13.0 \%)$ & 0.34 \\
\hline FAST scan \% $(n=109)$ & $12(11.0 \%)$ & $8(9.2 \%)$ & $4(18.2 \%)$ & 0.22 \\
\hline Blood transfusion \% & 47 (39.5\%) & $34(35.4 \%)$ & $13(56.5 \%)$ & 0.06 \\
\hline Number of blood units (median and range) & $3(1-51)$ & $4(1-29)$ & $2(1-51)$ & 0.52 \\
\hline Massive blood transfusion \% & $8(6.7 \%)$ & $5(5.2 \%)$ & $3(13.0 \%)$ & 0.17 \\
\hline \multicolumn{5}{|l|}{ In-hospital complications \% } \\
\hline Pneumonia & $8(6.7 \%)$ & $7(7.3 \%)$ & $1(4.3 \%)$ & 0.61 \\
\hline Sepsis & $2(1.7 \%)$ & $1(1.0 \%)$ & $1(4.3 \%)$ & 0.26 \\
\hline ARDS & $1(0.8 \%)$ & $0(0.0 \%)$ & $1(4.3 \%)$ & 0.43 \\
\hline Acute Kidney Injury & $4(3.4 \%)$ & $3(3.1 \%)$ & $1(4.3 \%)$ & 0.77 \\
\hline Deep vein thrombosis & $1(0.8 \%)$ & $1(1.0 \%)$ & $0(0.0 \%)$ & 0.62 \\
\hline Ventilatory days (median and range) & $7(1-31)$ & $6(1-31)$ & $7(3-27)$ & 0.60 \\
\hline ICU length of stay (median and range) & $4(1-35)$ & $4(1-33)$ & $4.5(1-35)$ & 0.93 \\
\hline Hospital length of stay (median and range) & $10(1-85)$ & $9(1-85)$ & $13(1-74)$ & 0.17 \\
\hline Mortality \% & $3(2.5 \%)$ & $2(2.1 \%)$ & $1(4.3 \%)$ & 0.53 \\
\hline
\end{tabular}


The mean ISS was $16.2 \pm 11$, RTS was $7.3 \pm 1.2$ and pelvic AIS was $2.2 \pm 0.5$. The majority of patient were stable and were admitted to the floor $(68 ; 57.1 \%)$, whereas 21 $(17.6 \%)$ patients were transferred directly to operating room and 28 (23.5\%) were admitted to ICU. The median ICU stay was 4 days (1-35) and the hospital length of stay was 10 days (1-85).

Table 1 compares the demographics, clinical presentation and outcome of pelvic fracture based on management. The two groups were comparable for demographics, mechanism of injury, injury severity and associated injuries except for chest injuries which were significantly higher in the conservatively treated group $(51.0 \%$ vs. $26.1 \%, p=0.03)$ than the surgical group. Patients in the surgical group were more likely to have higher pelvis AIS $(p=0.001)$, type IV fractures $(p=0.001)$, acetabular fractures $(p=0.001)$ and closed triradiate cartilage $(p=0.04)$ as compared to conservative group. On the other hand, type III fractures and open triradiate cartilage were significantly higher in the conservative group $(p<0.05)$. However, the rate of in-hospital complications and mortality did not differ significantly among the two groups.

Table 2 shows the clinical characteristics and outcome by types of pelvic ring fractures (Torode classification). Out of 109 pelvic ring fractures, 104 were classified and 5 were unclassified. The most common was type III (68.3\%) followed by type II (13.5\%), type IV (12.5\%) and type I (5.8\%). The distribution of age, gender, mechanism of injury, associated injuries, injury severity scores and presence of open or closed triradiate cartilage. Patients with type IV fractures were more likely to have mean higher pelvis AIS $(p=0.001)$ and surgical intervention ( $p=0.001)$ as compared to other groups. Whereas, most lower grade fractures were treated conservatively (Fig. 1).

The need for massive blood transfusion, in-hospital complications and mortality tended to be more in

Table 2 Comparison of clinical presentation and outcome of paediatric pelvic fracture based on Torode fracture classification

\begin{tabular}{|c|c|c|c|c|c|}
\hline & Type I $(n=6)$ & Type II $(n=14)$ & Type III $(n=71)$ & Type IV $(n=13)$ & $P$ value \\
\hline Age (mean \pm SD) & $10.4 \pm 6.4$ & $9.0 \pm 6.7$ & $11.1 \pm 5.7$ & $13.3 \pm 5.3$ & 0.30 \\
\hline Males \% & $4(66.7 \%)$ & $10(71.4 \%)$ & $55(77.5 \%)$ & $10(76.9 \%)$ & 0.91 \\
\hline \multicolumn{6}{|l|}{ Associated injuries \% } \\
\hline Chest & $4(66.7 \%)$ & $7(50.0 \%)$ & $35(49.3 \%)$ & $5(38.5 \%)$ & 0.72 \\
\hline Spine & $1(16.7 \%)$ & $1(7.1 \%)$ & $18(25.4 \%)$ & $4(30.8 \%)$ & 0.42 \\
\hline Abdomen & $3(50.0 \%)$ & $4(28.6 \%)$ & $27(38.0 \%)$ & $6(46.2 \%)$ & 0.74 \\
\hline Head & $2(33.3 \%)$ & $3(21.4 \%)$ & $20(28.2 \%)$ & $1(7.7 \%)$ & 0.42 \\
\hline Lower extremity & $2(33.3 \%)$ & $2(14.3 \%)$ & $11(15.5 \%)$ & $2(15.4 \%)$ & 0.71 \\
\hline Injury Severity Score (mean \pm SD) & $21.0 \pm 9.5$ & $14.1 \pm 8.7$ & $15.7 \pm 11.0$ & $21.9 \pm 15.8$ & 0.19 \\
\hline Revised Trauma Score & $7.8 \pm 0.1$ & $7.0 \pm 1.3$ & $7.2 \pm 1.3$ & $7.7 \pm 0.4$ & 0.30 \\
\hline Pelvis AIS & $2.2 \pm 0.4$ & $2.1 \pm 0.3$ & $2.2 \pm 0.4$ & $2.9 \pm 1.1$ & 0.001 \\
\hline Open triradiate cartilage $\%$ & $1(33.3 \%)$ & $10(71.4 \%)$ & $41(58.6 \%)$ & $4(36.4 \%)$ & 0.27 \\
\hline Closed triradiate cartilage $\%$ & $2(66.7 \%)$ & $4(28.6 \%)$ & $29(41.4 \%)$ & $7(63.6 \%)$ & \\
\hline \multicolumn{6}{|l|}{ Management \% } \\
\hline Conservative management & $6(100 \%)$ & $13(92.9 \%)$ & $67(94.4 \%)$ & $1(7.7 \%)$ & 0.001 for all \\
\hline Surgical intervention & $0(0.0 \%)$ & $1(7.1 \%)$ & $4(5.6 \%)$ & $12(92.3 \%)$ & \\
\hline Blood transfusion & $3(50.0 \%)$ & $6(42.9 \%)$ & $26(36.6 \%)$ & $7(53.8 \%)$ & 0.64 \\
\hline Massive blood transfusion & $0(0.0 \%)$ & $1(7.1 \%)$ & $4(5.6 \%)$ & $2(15.4 \%)$ & 0.54 \\
\hline \multicolumn{6}{|l|}{ In-hospital complications \% } \\
\hline Pneumonia & $0(0.0 \%)$ & $1(7.1 \%)$ & $6(8.5 \%)$ & $0(0.0 \%)$ & 0.63 \\
\hline Sepsis & $0(0.0 \%)$ & $0(0.0 \%)$ & $2(2.8 \%)$ & $0(0.0 \%)$ & 0.81 \\
\hline ARDS & $0(0.0 \%)$ & $0(0.0 \%)$ & $0(0.0 \%)$ & $1(7.7 \%)$ & 0.07 \\
\hline Acute Kidney Injury & $0(0.0 \%)$ & $1(7.1 \%)$ & $2(2.8 \%)$ & $1(7.7 \%)$ & 0.71 \\
\hline Deep vein thrombosis & 0 & 0 & $1(1.4 \%)$ & 0 & - \\
\hline ICU length of stay (median and range) & $2.5(2-3)$ & $5(2-12)$ & $5(1-35)$ & $4(1-7)$ & 0.44 \\
\hline Hospital length of stay (median and range) & $13.5(1-40)$ & $5(1-36)$ & $9(1-85)$ & $13(1-44)$ & 0.15 \\
\hline Mortality \% & $0(0.0 \%)$ & $1(7.1 \%)$ & $1(1.4 \%)$ & $1(7.7 \%)$ & 0.43 \\
\hline
\end{tabular}


patients with higher facture grades (type III \& IV) but did not reach statistical significance (Table 2).

Acetabulum fractures: Ten patients had acetabular fractures and were males, with mean age of $15.3 \pm 1.4$ years. They frequently involved in MVC and had more spinal and extremities associated injuries and half of them received blood transfusion. The mean ISS of patients with acetabulum fracture was lower than those with pelvic ring fracture $(12.8 \pm 5.4$ vs. $16.5 \pm 11.4 ; p=$ 0.09). Also, patients with acetabular fracture had shorter hospital course which may be due to better bony support for ambulation when compared to the immature paediatric pelvis and none of them developed in-hospital complications as compared to those with pelvic ring fracture.

Open versus closed triradiate: Comparison of clinical characteristics and outcomes of patients with open versus closed triradiate are shown in Table 3 and Fig. 1. There were $56(51.4 \%)$ patients with open triradiate cartilage and $53(48.6 \%)$ had closed triradiate cartilage. The closed group was significantly older in age $(p=0.001)$, predominantly males $(p=0.04)$ involved in MVC. Pedestrian hit by motor vehicle was the most common injury mechanism in the open group $(p=0.001)$. Also, patients with closed triradiate cartilage frequently sustained spine $(p=0.001)$ and head $(p=0.01)$ injuries, acetabular fracture $(p=0.001)$ and had higher mean ISS $(p=0.002)$ and pelvis AIS $(p=0.03)$ than the open group. The two groups were comparable for pelvic fracture classification, rate of intubation, massive blood transfusion, in-hospital complications and mortality. Patients with open triradiate cartilage were more likely to be treated conservatively whereas, closed group had significantly higher rate of surgical intervention $(p=0.04)$. The need for blood transfusion $(p=0.005)$, ventilatory days $(p=0.03)$, length of ICU $(p=0.005)$ and hospital stay $(p=0.001)$ were significantly higher in patients with closed triradiate cartilage compared to the open group. Figure 2 shows examples of hip X-ray after non-operative treatment, skeletal traction and surgically treated pediatric pelvic fractures.

Table 4 shows the type of surgical intervention based of the fracture classification.

\section{Discussion}

This is a single center study that describes a 3 and half year experience for the prevalence, clinical characteristics, injury pattern and management of PPF at the only level I trauma center in Qatar. Pelvic fracture in the pediatric population is uncommon which corresponds to $2.3 \%$ of the total trauma admissions in our centre. The key findings of this study include the predominance of male gender, MVC as major mechanism of injury; chest and abdomen were the frequently associated injured body regions. In addition, patients who required surgical intervention sustained severer pelvic injuries with higher pelvis AIS, frequent type IV fractures, acetabular fractures and closed triradiate cartilage. However, the rate of in-hospital complications and mortality did not differ significantly with respect to management, type of fracture and open or closed triradiate cartilage.

The high-energy trauma includes MVC, pedestrian hit by a car and falling from height results in pelvic fracture of immature bone in children and is an indicator of the presence of associated injuries [18, 19]. The present study observed traffic accidents as the most common mechanism of injury which is similar to that of the adult pelvic fracture patients [20]; a finding that was reported by several earlier studies $[4,9,10,18,19]$.

Despite the similar injury mechanism causing pelvic fracture in adults, the pattern of fracture among pediatric patients seems to be more stable [14, 18]. Therefore, the clinically useful classification could facilitate the prediction of the disease process's natural history and guide in selecting the appropriate management strategy. Torode and Zieg classification [17] is the widely used system for pediatric pelvic fractures. This system attributes both anatomic and mechanical factors to the severity of the deformity. However, it did not consider the bony pelvis' changing maturity throughout the children's age range. In our cohort, Torode type III was the most common pelvic ring injury $(68.3 \%)$ which is similar to what has been reported previously $[6,8,18]$. On the other hand, Niedzielki et al. [21] reported that the frequent type of fracture among children is avulsion fractures secondary to sports injuries. The fracture classification influences the management plan for fracture and predicts length of hospital stay and outcomes. In our study, patients with type IV fractures were more likely to undergo surgical intervention.

Associated pelvic hematoma is less common in children when compared to adults and more easily controlled [12]. In our cohort, only 7 patients were identified to have pelvic hematoma. Rapid fatal exsanguination due to pelvic fracture is extremely rare in children, while it is the leading and common cause for early mortality in adult polytrauma patients. This difference may be due to the vasoactive proprieties of pediatric blood vessels that undergoes more vasoconstriction as compared to the more friable atherosclerotic adult vessels $[12,22]$. Around $17-46 \%$ of pediatrics trauma victims with pelvic fracture required blood transfusion. However, it appears that the indication for the transfusion is mainly to restore the RBC mass rather than the resuscitation of life-threatening hypovolemia and usually, there is no need for embolization to control the bleeding. Concomitant solid visceral injury causes bleeding 
Table 3 Demographics, and clinical presentation according to triradiate cartilage fractures $(n=109)$

\begin{tabular}{|c|c|c|c|}
\hline & Open triradiate cartilage $(n=56)$ & Closed triradiate cartilage $(n=53)$ & $P$ value \\
\hline Age (mean \pm SD) & $6.9 \pm 4.2$ & $16.4 \pm 1.6$ & 0.001 \\
\hline Males \% & $40(71.4 \%)$ & $46(86.8 \%)$ & 0.04 \\
\hline \multicolumn{4}{|l|}{ Mechanism of injury \% } \\
\hline Motor vehicle crashes & $16(28.6 \%)$ & $41(77.4 \%)$ & \multirow[t]{4}{*}{0.001 for all } \\
\hline Fall & $9(16.1 \%)$ & $5(9.4 \%)$ & \\
\hline Pedestrian & $25(44.6 \%)$ & $1(1.9 \%)$ & \\
\hline Others & $6(10.7 \%)$ & $6(11.3 \%)$ & \\
\hline \multicolumn{4}{|l|}{ Associated injuries \% } \\
\hline Chest & $22(39.3 \%)$ & $26(49.1 \%)$ & 0.30 \\
\hline Spine & $4(7.1 \%)$ & $22(41.5 \%)$ & 0.001 \\
\hline Abdomen & $16(28.6 \%)$ & $24(45.3 \%)$ & 0.07 \\
\hline Head & $8(14.3 \%)$ & $18(34.0 \%)$ & 0.01 \\
\hline Lower extremity & $7(12.5 \%)$ & $13(24.5 \%)$ & 0.10 \\
\hline Injury Severity Score (mean \pm SD) & $12.8 \pm 9.9$ & $19.3 \pm 11.6$ & 0.002 \\
\hline Revised Trauma Score (mean \pm SD) & $7.6 \pm 0.9$ & $7.2 \pm 1.3$ & 0.06 \\
\hline Pelvis abbreviated injury score (mean \pm SD) & $2.1 \pm 0.4$ & $2.4 \pm 0.7$ & 0.03 \\
\hline \multicolumn{4}{|l|}{ Torode fracture classification $\%$} \\
\hline Type I & $1(1.8 \%)$ & $2(4.8 \%)$ & \multirow[t]{4}{*}{0.27 for all } \\
\hline Type ॥ & $10(17.9 \%)$ & $4(9.5 \%)$ & \\
\hline Type III & $41(73.2 \%)$ & $29(69.0 \%)$ & \\
\hline Type IV & $4(7.1 \%)$ & $7(16.7 \%)$ & \\
\hline Acetabular fracture $\%$ & $0(0.0 \%)$ & $9(17.0 \%)$ & 0.001 \\
\hline \multicolumn{4}{|l|}{ Management \% } \\
\hline Conservative management & 49 (87.5\%) & $38(71.7 \%)$ & \multirow[t]{2}{*}{0.04} \\
\hline Surgical intervention & $7(12.5 \%)$ & $15(28.3 \%)$ & \\
\hline Intubation \% & $8(14.3 \%)$ & $14(26.4 \%)$ & 0.11 \\
\hline Positive FAST scan \% & $4(7.5 \%)$ & $8(17.0 \%)$ & 0.14 \\
\hline Number of blood units (median and range) & $2(1-12)$ & $4(1-51)$ & 0.06 \\
\hline Blood transfusion \% & $15(26.8 \%)$ & $28(52.8 \%)$ & 0.005 \\
\hline Massive blood transfusion \% & $2(3.6 \%)$ & $5(9.4 \%)$ & 0.21 \\
\hline \multicolumn{4}{|l|}{ In-hospital complications \% } \\
\hline Pneumonia & $0(0.0 \%)$ & $6(11.3 \%)$ & 0.10 \\
\hline Sepsis & $0(0.0 \%)$ & $2(3.8 \%)$ & 0.14 \\
\hline ARDS & $0(0.0 \%)$ & $1(1.9 \%)$ & 0.30 \\
\hline Acute Kidney Injury & $1(1.8 \%)$ & $3(5.7 \%)$ & 0.28 \\
\hline Ventilatory days (median and range) & $2(1-10)$ & $9(1-31)$ & 0.03 \\
\hline ICU length of stay (median and range) & $2.5(1-15)$ & $7(2-35)$ & 0.005 \\
\hline Hospital length of stay (median and range) & $6(1-76)$ & $14(1-85)$ & 0.001 \\
\hline Mortality \% & $1(1.8 \%)$ & $2(3.8 \%)$ & 0.52 \\
\hline
\end{tabular}

and the incidence of intra-abdominal organ injury varied between 10 and 20\%. Also, the pelvic hematoma is not a significant contributing factor for mortality $[12,14]$.

Earlier studies demonstrated an association between other injuries and pelvic fracture that may leads to early or late mortality, if not managed timely [4, 23]. The present study showed chest injury to be the most common associated injury followed by abdominal and head injuries in pediatric polytrauma patients. These findings are consistent with earlier report [4]. Whereas, others 

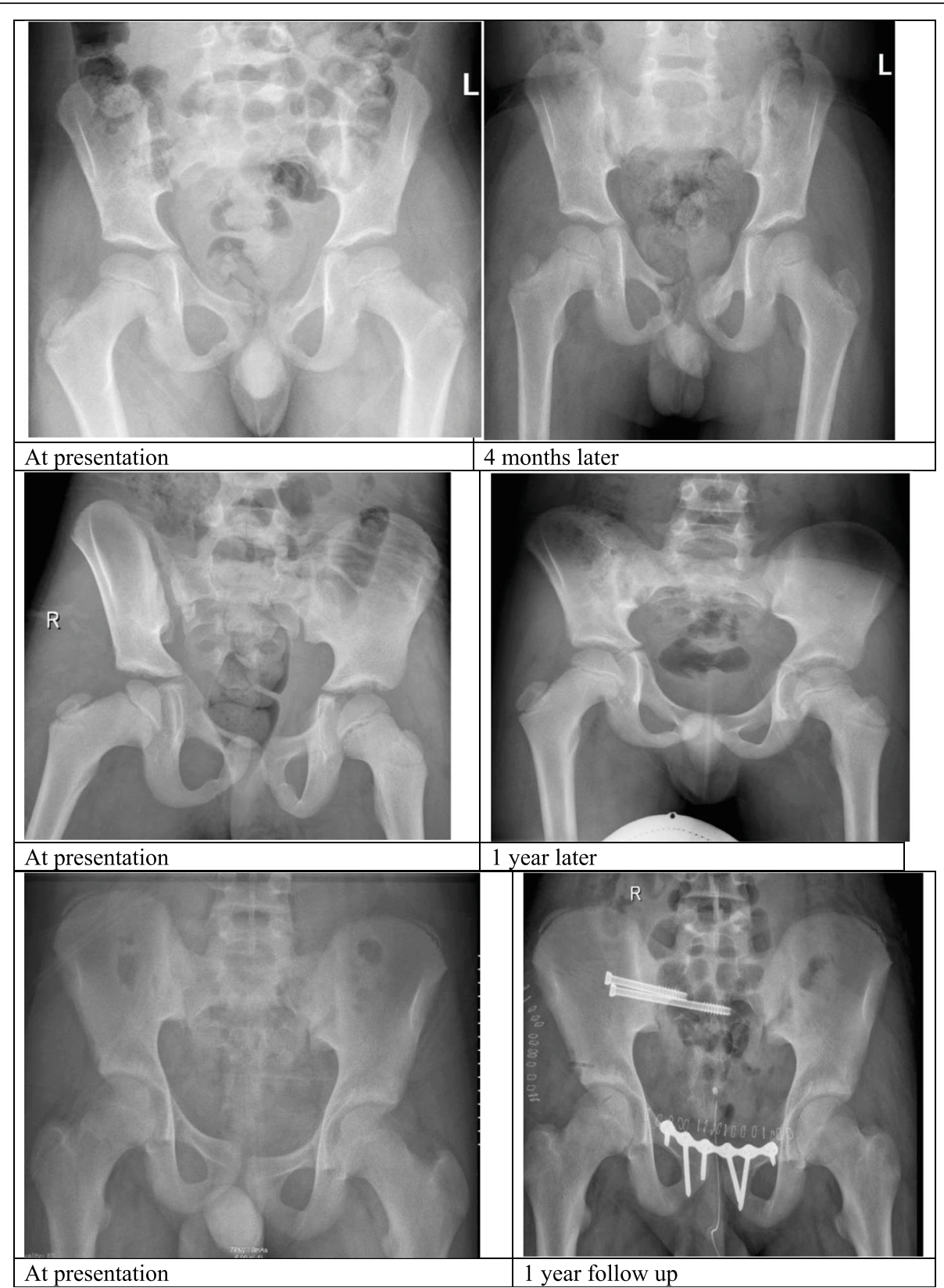

Fig. 2 Hip X-ray before and after treatment of pediatric pelvic fractures: the upper panel shows Torode type III, treated non-operatively by nonweight bearing for 6 years old patient. The middle panel shows Torode type IV, treated by skeletal traction in 8 years old patient. The lower panel shows Torode type IV, treated by open reduction and internal fixation in 14 years old patient

reported the head as frequently associated injury than thorax and abdomen [5, 23]. On the other hand, femoral and tibia fractures were the most common associated fractures in the limbs. In contrast, spine fracture, mainly thoracic spine, was the most common associated fracture in the axial skeleton $[3,5,19]$ which is similar to our findings.

The 24-h mortality for pediatrics polytrauma patients is related to many factors, including the injury severity score; patients associated with higher ISS scores were hemodynamically unstable and required blood transfusion. Another major factor is the severity of the associated head injury. Death increased with the head AIS and other outcomes such as longer ICU stay. In our study the overall mortality is $2.5 \%$ and two out of three patients died due to concomitant head injury. Notably, the severity of pelvic ring injury was not associated with early mortality $[12,19,24,25]$. The increase in the mortality rate among adult polytrauma patients has been correlated with increased patient age, while this 
Table 4 Management of pelvic fracture

\begin{tabular}{|c|c|c|}
\hline $\begin{array}{l}\text { Torode classification and acetabulum } \\
\text { Fracture }\end{array}$ & $\begin{array}{l}\text { Open/Closed } \\
\text { triradiate }\end{array}$ & Type of surgery \\
\hline III & Closed & Left Sacroiliac screws \\
\hline IV & Open & k-wire fixation of Sacroiliac joint \\
\hline Acetabular fracture & Closed & Total Hip Replacement/acetabulum \\
\hline IV & Open & k-wire fixation of Sacroiliac joint/ORIF \\
\hline IV & Closed & Plating of iliac bone \\
\hline IV & Closed & Sacroiliac screw \\
\hline Acetabular fracture & Closed & Screw fixation \\
\hline Acetabular fracture & Closed & Acetabulum \\
\hline IV & Closed & Left Sacroiliac screw \\
\hline IV & Closed & Left Sacroiliac screw \\
\hline IV & $\mathrm{n} / \mathrm{a}$ & Pelvis and acetabulum ORIF (done abroad) \\
\hline III & Closed & Pelvis not fixed (only Right femur/hip DHS) \\
\hline IV & Open & Skeletal traction \\
\hline IV & Closed & ORIF, Sacroiliac screw, Symphysis pubis plating \\
\hline III & Open & Pelvis not fixed (only femur hip spica application) \\
\hline Acetabular fracture & Closed & Examination under anesthesia for right hip stability \\
\hline Acetabular fracture & Closed & ORIF \\
\hline IV & Open & skeletal traction \\
\hline III & Open & Treated non operatively \\
\hline IV & Closed & ORIF \\
\hline Acetabular fracture & Closed & Examination under anesthesia for left hip stability \\
\hline IV & Closed & Skeletal traction \\
\hline ॥ & Open & $\begin{array}{l}\text { Treated non operatively (only ORIF for left femur subtrochanteric } \\
\text { fracture) }\end{array}$ \\
\hline
\end{tabular}

DHS dynamic hip screw, ORIF open reduction internal fixation, $n / a$ not available

correlation was not observed in pediatrics polytrauma patients [12].

During adolescence the pediatric pelvic transforms into adult form and during this transition, the pelvis primarily loses elasticity, and the triradiate cartilage closure occurs at approximately 14 years of age in males and 12 years in females. In our study, around half of patients had open triradiate cartilage and half had closed triradiate cartilage. The closed group was older in age, predominantly males and had higher mean ISS and pelvis AIS. The biological transition has been suggested to distinguish pediatric pelvis from the adults and is an essential factor which may influence the treatment choices as well as the outcome $[6,14,26]$.

Earlier, most pelvic fracture cases were treated nonoperatively due to the possibility of pelvic remodeling during the successive growth in children like the long bone fracture [27]. However, Conservative treatment of unstable and displaced pelvic fracture may result in pelvic asymmetry leading to more serious disabilities and chronic pelvic pain like that of adults.
In the present study, patients with type IV fractures were more likely to have surgical intervention while lower grade fractures were treated conservatively. Prevention of deformity after displacement of pelvic fracture is one of the indications for surgical intervention in pediatric patients, which leads to more effective rehabilitation and nursing care $[2,28,29]$.

Limitations of this study include the retrospective design, and lack of follow-up (long-term) and quality of life data. The current study had less Torode type 1 avulsion injuries; this could be related to that those minor sports injuries were not admitted to the Level 1 trauma center. The present study is post-hoc analysis of traumatic pelvic injuries database that has been described previously [20]. Moreover, the pediatric age varied widely which potentially mix the biological differences between children and teenagers which tend to behave more like adults. Although maturation occurs earlier than the cut off in this report, we opted to the WHO definition of pediatric age cutoff. The time from injury to intervention was not 
captured in the database. We have included all patients with open as well as closed triradiate cartilage which differs from patient-to-patient depending on gender and bony growth. Open triradiate cartilage mostly were observed in younger children (mean age: $6.9 \pm 4.2$ years), whereas, adolescents (mean age: $16.4 \pm 1.6$ years) were more likely to have closed triradiate fractures in our cohort. The closure of the triradiate cartilage usually occurs at age of 15 in males and age of 13 in females [30].

\section{Conclusions}

This study shows that PPF are uncommon and mainly caused by high-impact trauma associated with multisystem injuries. The majority of pediatric fracture pattern are stable, despite the underlying high-energy mechanism due to the high plasticity and elasticity of bones. Polytrauma is the usual pattern that dictates the outcome rather than the fractures. Management of PPF mainly depends on the severity of fracture as patients with higher grade fractures require surgical intervention. Also, associated injuries should be managed appropriately to minimize the morbidity and mortality. Furthermore, larger prospective study is needed to understand the age-related pattern and management of PPF.

\section{Abbreviations}

AIS: Abbreviated injury scale; ISS: Injury severity score; PPF: Pediatric pelvic fractures; RTS: Revised trauma score

\section{Acknowledgments}

The authors thank all the staff of the trauma registry database at the trauma surgery section.

\section{Financial disclosure}

None.

\section{Authors' contributions}

AA: study design, data collection, data interpretation, writing and approval of manuscript. IM: study design, data collection, data interpretation, writing and approval of manuscript. HA: study design, data collection, data interpretation, writing and approval of manuscript. Sl: study design, data collection, data interpretation, writing and approval of manuscript. MA: data entry, interpretation, statistical analysis, writing and approval of manuscript. EB: study design, data collection, data interpretation, writing and approval of manuscript. HAt: study design, data interpretation, writing and approval of manuscript.

AE: study design, data interpretation, writing and approval of manuscript.

\section{Funding}

None.

\section{Availability of data and materials}

All data generated or analyzed during this study are included in this manuscript. De-identified data are accessible upon agreement with the national trauma registry and the medical research centre at Hamad Medical Corporation (contact: mrchelpdesk@hamad.qa).

\section{Declarations}

\section{Competing interest}

The authors declare no conflict of interest.

\section{Ethics approval and consent to participate}

This observational retrospective study received expedited review as data were anonymous with no direct contact with subjects and was approved by the Institutional Review Board (IRB) at Hamad Medical Corporation, Medical Research Center; IRB\# 16395/16). All methods were carried out in accordance with relevant guidelines and regulations. The need for informed consent was waived by the ethics committee at Hamad Medical Corporation.

\section{Consent for publication}

Not applicable.

\section{Author details}

'Department of Surgery, Orthopedic Surgery, Hamad General Hospital, Doha, Qatar. ${ }^{2}$ Department of Surgery, Trauma Surgery, Hamad General Hospital, Doha, Qatar. ${ }^{3}$ Clinical Research, Trauma \& Vascular Surgery, Department of Surgery, Hamad General Hospital, HMC, Doha, Qatar. ${ }^{4}$ Department of Clinical Medicine, Weill Cornell Medical School, Doha, Qatar.

Received: 28 April 2021 Accepted: 7 June 2021

Published online: 16 July 2021

\section{References}

1. Zwingmann J, Lefering R, Maier D, Hohloch L, Eberbach H, Neumann M, et al. Pelvic fractures in severely injured children: results from the TraumaRegister DGU. Medicine (Baltimore). 2018;97(35):e1 1955. https://doi. org/10.1097/MD.0000000000011955.

2. Gänsslen A, Heidari N, Weinberg AM. Fractures of the pelvis in children: a review of the literature. Eur J Orthop Surg Traumatol. 2013;23(8):847-61. https://doi.org/10.1007/s00590-012-1102-0.

3. Hermans E, Cornelisse ST, Biert J, Tan ECTH, Edwards MJR. Paediatric pelvic fractures: how do they differ from adults? J Child Orthop. 2017;11(1):49-56 https://doi.org/10.1302/1863-2548-11-160138.

4. Banerjee S, Barry MJ, Paterson JM. Paediatric pelvic fractures: 10 years experience in a trauma centre. Injury. 2009;40(4):410-3. https://doi.org/10.1 016/j.injury.2008.10.019.

5. Silber JS, Flynn JM, Koffler KM, Dormans JP, Drummond DS. Analysis of the cause, classification, and associated injuries of 166 consecutive pediatric pelvic fractures. J Pediatr Orthop. 2001;21(4):446-50.

6. Shore BJ, Palmer CS, Bevin C, Johnson MB, Torode IP. Pediatric pelvic fracture: a modification of a preexisting classification. J Pediatr Orthop. 2012; 32(2):162-8.

7. Silber JS, Flynn JM. Changing patterns of pediatric pelvic fractures with skeletal maturation: implications for classification and management. J Pediatr Orthop. 2002;22(1):22-6.

8. Guerra MR, Braga SR, Akkari M, Santili C. Pelvic injury in childhood: what is its current importance? Acta Ortop Bras. 2016;24(3):155-8. https://doi.org/1 0.1590/1413-785220162403157540.

9. Spiguel L, Glynn L, Liu D, Statter M. Pediatric pelvic fractures: a marker for injury severity. Am Surg. 2006;72(6):481-4.

10. Tuovinen H, Söderlund T, Lindahl J, Laine T, Åström P, Handolin L. Severe pelvic fracture-related bleeding in pediatric patients: does it occur? Eur J Trauma Emerg Surg. 2012;38(2):163-9. https://doi.org/10.1007/s00068-011-0140-3.

11. Hauschild O, Strohm PC, Culemann U, Pohlemann T, Suedkamp NP, Koestler W, et al. Mortality in patients with pelvic fractures: results from the German pelvic injury register. J Trauma. 2008;64(2):449-55. https://doi.org/10.1097/ TA.0b013e31815982b1

12. Ismail N, Bellemare JF, Mollitt DL, DiScala C, Koeppel B, Tepas JJ 3rd. Death from pelvic fracture: children are different. J Pediatr Surg. 1996;31(1):82-5. https://doi.org/10.1016/s0022-3468(96)90324-3.

13. Desai AA, Gonzalez KW, Juang D. Pelvic trauma. J Pediatr Intens Care. 2015; 4(1):40-6. https://doi.org/10.1055/s-0035-1554988.

14. Bent MA, Hennrikus WL, Latorre JE, Armstrong DG, Shaw B, Jones KC, et al. Role of computed tomography in the classification of pediatric pelvic fractures-revisited. J Orthop Trauma. 2017;31(7):e200-4

15. Silber JS, Flynn JM, Katz MA, Ganley TJ, Koffler KM, Drummond DS. Role of computed tomography in the classification and management of pediatric pelvic fractures. J Pediatr Orthop. 2001;21(2):148-51.

16. Spina M, Luppi V, Chiappi J, Bagnis F, Rocca G. Triradiate cartilage fracture of the acetabulum treated surgically. Acta Biomed. 2019;90(1):116-21. https:// doi.org/10.23750/abm.v90i1.7263.

17. Torode I, Zieg D. Pelvic fractures in children. J Pediatr Orthop. 1985;5:76-84. 
18. de la Calva C, Jover N, Alonso J, Salom M. Pediatric pelvic fractures and differences compared with the adult population. Pediatr Emerg Care. 2020; 36(11):519-22. https://doi.org/10.1097/PEC.0000000000001411.

19. Tosounidis TH, Sheikh H, Giannoudis PV. Pelvic fractures in paediatric polytrauma patients: classification, concomitant injuries and early mortality. Open Orthop J. 2015;9:303-12. https://doi.org/10.2174/187432 5001509010303

20. Abdelrahman $\mathrm{H}$, El-Menyar A, Keil H, Alhammoud A, Ghouri SI, Babikir E, et al. Patterns, management, and outcomes of traumatic pelvic fracture: insights from a multicenter study. J Orthop Surg Res. 2020;15(1):249. https:// doi.org/10.1186/s13018-020-01772-w.

21. Niedzielski KR, Guzikiewicz N, Małecki K, Golański G. Pelvic fractures in children and adolescents in polytrauma and high-energy injuries. Ortop Traumatol Rehabil. 2013;15(1):41-8.

22. Grisoni N, Connor S, Marsh E, Thompson GH, Cooperman DR, Blakemore LC. Pelvic fractures in a pediatric level I trauma center. J Orthop Trauma. 2002; 16(7):458-63.

23. Chia JP, Holland AJ, Little D, Cass DT. Pelvic fractures and associated injuries in children. J Trauma. 2004;56(1):83-8.

24. Leonard M, Ibrahim M, Mckenna P, Boran S, McCormack D. Paediatric pelvic ring fractures and associated injuries. Injury. 2011;42(10):1027-30.

25. Vitale MG, Kessler MW, Choe JC, Hwang MW, Tolo VT, Skaggs DL. Pelvic fractures in children: an exploration of practice patterns and patient outcomes. J Pediatr Orthop. 2005;25(5):581-7.

26. Holden CP, Holman J, Herman MJ. Pediatric pelvic fractures. J Am Acad Orthop Surg. 2007;15(3):172-7.

27. Schwarz N, Posch E, Mayr J, Fischmeister FM, Schwarz AF, Ohner T. Longterm results of unstable pelvic ring fractures in children. Injury. 1998;29(6): 431-3.

28. Oransky M, Arduini M, Tortora M, Zoppi AR. Surgical treatment of unstable pelvic fracture in children: long term results. Injury. 2010;41(11):1140-4.

29. Pascarella R, Bettuzzi C, Digennaro V. Surgical treatment for pelvic ring fractures in pediatric and adolescence age. Musculoskelet Surg. 2013;97(3): $217-22$

30. Dimeglio A, Canavese F. Progression or not progression? How to deal with adolescent idiopathic scoliosis during puberty. J Child Orthop. 2013;7(1):43-9.

\section{Publisher's Note}

Springer Nature remains neutral with regard to jurisdictional claims in published maps and institutional affiliations.

Ready to submit your research? Choose BMC and benefit from:

- fast, convenient online submission

- thorough peer review by experienced researchers in your field

- rapid publication on acceptance

- support for research data, including large and complex data types

- gold Open Access which fosters wider collaboration and increased citations

- maximum visibility for your research: over $100 \mathrm{M}$ website views per year

At $\mathrm{BMC}$, research is always in progress.

Learn more biomedcentral.com/submissions 